\title{
Unintentional injuries in children and youth from immigrant families in Ontario, Canada: a population-based cross- sectional study
}

\author{
Natasha Ruth Saunders MSc MD, Alison Macpherson PhD, Jun Guan MSc, Lisa Sheng MD PhD, \\ Astrid Guttmann MSc MDCM
}

\section{Abstract}

Background: Unintentional injury is the leading cause of childhood death. Injury is associated with a number of sociodemographic characteristics, but little is known about risk in immigrants. Our objective was to examine the association between family immigrant status and unintentional injury in children and youth.

Methods: We performed a population-based, cross-sectional study involving children and youth (age 0-24 yr) residing in Ontario from 2008 to 2012. Multiple linked health and administrative databases were used to describe unintentional injuries by family immigrant status. Unintentional injury events (e.g., emergency department visits, admissions to hospital, deaths) were analyzed using Poisson regression models to estimate rate ratios (RRs) for injury by immigrant status.

Results: Annualized injury rates were 11749 emergency department visits per 100000 population, 267 hospital admissions per 100000 population and 12 deaths per 100000 population. Injury rates were lower among immigrants across all causes of unintentional injury (adjusted RR 0.56, 95\% confidence interval [Cl] 0.54-0.59). Among nonimmigrants, lowest neighbourhood income quintile was associated with the highest rates (RR 1.13, 95\% $\mathrm{Cl} 1.08-1.18$, quintile 5 v. 1); among immigrants, lowest income quintile was associated with the lowest rates of injury (RR $0.88,95 \% \mathrm{Cl} 0.82-0.94$, quintile $5 \mathrm{v}$. 1). Highest rates of injury for nonimmigrants were among adolescents (age 10-14 yr, RR 1.23, 95\% Cl 1.18-1.28; v. 20-24 yr), but for immigrants, was highest among young children (0-4 yr RR 1.23, 95\% Cl 1.16-1.31; v. 20-24 yr).

Interpretation: Rates of unintentional injury are lower among immigrant than among Canadian-born children, supporting a healthy immigrant effect. Socioeconomic status and age have different associations with injury risk, suggesting alternative causal pathways for injuries in immigrant children and youth.

T njury is one of the leading causes of visits to the emergency department and is the leading cause of death for children and youth in Canada and other high-income countries. ${ }^{1-3}$ Although some minor injuries (scrapes and bruises) occur during physical activity and may reflect healthy, active living, many injuries cause some degree of harm and are preventable. Epidemiologic literature has identified a number of risk factors for unintentional childhood injuries. Adolescent boys have consistently been shown to be at highest risk of injuries that require medical attention compared with girls and younger children. ${ }^{3-5}$ Children living in rural areas have higher per capita rates of bicycle-related head injuries compared with children in urban settings, ${ }^{6}$ and children from lower income neighbourhoods or families are more likely to be injured. ${ }^{7-11}$ A number of important policies and by-laws have been implemented over the past 2 decades in Ontario and elsewhere, such as mandatory bicycle helmets for minors, ${ }^{12-14}$ maximum water temperature by-laws for residential hot water heaters ${ }^{15}$ and improved playground safety standards ${ }^{16}$ which have all effectively reduced injury rates in

Competing interests: None declared.

This article has been peer reviewed.

Correspondence to: Astrid Guttmann, Astrid.guttmann@ices.on.ca CMAJ Open 2017. DOI:10.9778/cmajo.20160099 
youth. ${ }^{7,13,17-19}$ Despite these important strides, preventable injuries continue to occur, suggesting room for improvement in policy development in addition to education and behaviour modification for families to prevent injury, particularly in high-risk groups. Identifying such groups, in particular by cause of injury, is important for effective injury prevention strategies.

One particular group that demands our attention is youths from immigrant families. Immigrants now make up about $20 \%$ of the Canadian population..$^{20}$ Exposures before and after migration, including home country safety standards, cultural norms and housing environment, may influence risk-taking behaviours and awareness and implementation of safety standards. Known sociodemographic predictors of injury in the general population may have a different effect in immigrant populations. There is a paucity of published data describing injuries in immigrant children $^{21,22}$ and the literature reporting risk of injury in European and American immigrants is either conflicting or limited to adult occupational, race-related injuries. ${ }^{9,23-31}$ It is not known whether the healthy immigrant effect, the notion that immigrants arrive in better health despite facing social disadvantage, extends to injury outcomes. ${ }^{32}$ Moreover, data on patterns of all-cause visits to the emergency department by immigrants has suggested a lower proportion of visits for injury compared with nonimmigrant children. ${ }^{33}$

Capitalizing on population-based linked data sources, our objectives were to determine the prevalence of unintentional injury-related visits to emergency departments, admissions to hospitals and deaths both overall and according to cause of injury among children and youth from immigrant families in Ontario, and to test the association of unintentional injury and immigrant status, controlling for other important predictors. We hypothesized immigrants' risk of injury would be lower compared with children from nonimmigrant families.

\section{Methods}

\section{Setting}

This study took place in Ontario, Canada's most populous province (population about 13 million) and used outcome data collected from Jan. 1, 2008, to Dec. 31, 2012. Individual characteristics of participants who met the study's inclusion criteria were collected from Jan. 1, 1985, to Dec. 31, 2012.

\section{Study design}

We performed a population-based cross-sectional study using data available at the Institute for Clinical Evaluative Sciences (ICES) through a research agreement from the Ontario Ministry of Health and Long-Term Care.

\section{Data sources}

Data from health administrative and demographic databases were linked using unique, encoded health identification numbers. Ontario has a single-payer universal Ontario Health Insurance Plan (OHIP), through which residents are insured for medically necessary care from physicians and hospitals. Immigrants admitted to Canada as permanent residents are typically eligible for OHIP after 3 months of residing in Ontario. Ontario's health care registry, the Registered Persons Database, contains sociodemographic information for all residents eligible for OHIP and includes their age, sex and postal code. The Canadian Institute for Health Information Discharge Abstract Database and National Ambulatory Care Reporting System contain diagnoses during hospital admissions and visits to Ontario emergency departments, respectively. Record linkage for these diagnostic codes are $97.5 \%-99.9 \% .{ }^{34}$ Injury-related deaths that occurred both in and out of hospital were ascertained from the Ontario Registrar General — Death with cause-of-death linkage at $97.4 \% .{ }^{34}$ Neighbourhood income quintile was obtained using Statistics Canada's Postal Code conversion file to link a patient's postal code at the dissemination area level (400-700 people) using the Rurality Index of Ontario, a census-derived rurality score. ${ }^{36}$

The Permanent Resident Data System, a federal database maintained by Immigration, Refugees and Citizenship Canada, holds sociodemographic and immigration information on all permanent residents who landed in Ontario from Jan. 1,1985 , to the present. Permanent residents are immigrants who have been granted to the right to stay and work in Canada without limitations on their stay. This database does not include data on temporary or undocumented immigrants. Information is collected from official immigration documents upon landing. Overall probabilistic linkage to the Registered Persons Database identifies about $86 \%$ of immigrants. ${ }^{37,38}$ The MOMBABY database, derived at ICES, pairs mothers with their newborns delivered in Ontario hospitals. It links inpatient admission records of delivering mothers and their newborns with linkage rates of more than $96 \% .{ }^{34}$ Through this database, newborns born in Canada to immigrant mothers were identified.

\section{Study population}

The study population included all children and youth from birth to 24 years of age who resided in Ontario with a valid OHIP number from Jan. 1, 2008, to Dec. 31, 2012. Records with a missing health card number, age or sex were excluded.

Participants entered the study on Jan. 1, 2008, or upon their birth, whichever occurred first. Study exit was either the end of study (Dec. 31, 2012) or Dec. 31 of the year the participant turned 25 years of age.

\section{Outcome measures}

The main outcome measure was unintentional injury-related hospital visit (emergency department visit, hospital admission, death) and out-of-hospital injury-related death. The cause of injury was grouped according to the International Classification of Diseases, 10th revision, (ICD-10) External Cause of Injury codes. ${ }^{39}$ Multiple visits for the same patient were included; however, only 1 event per patient per day was included. Duplicated, overlapping or transferred emergency department visits and hospital admissions were excluded. 


\section{Predictor}

The main exposure was immigrant status. Immigrants were defined as any child or youth who was a permanent resident (landed immigrant) who arrived in Canada after Jan. 1, 1985, or any child or youth with a mother who was a permanent resident who arrived in Canada after Jan. 1, 1985. Children of immigrant mothers arriving before development of the Permanent Resident Data System in 1985 were considered nonimmigrants. Maternal immigrant status was included to show injury outcomes related to the family unit or environment, rather than only to the child.

\section{Covariates}

We included a number of relevant covariates potentially associated with injury based on the literature or clinical plausibility. Adolescents and boys have both been shown to have higher risk of injury compared with children and girls, 4,40 and therefore age and sex were included. Neighbourhood income quintile at the time of injury and urban or rural residence were included because low income and rural residence have been associated with risk of injury. ${ }^{6,8,11,14}$ Demographic characteristics were based on information from health records during each study year.

\section{Statistical analysis}

Descriptive statistics were performed for the main exposure and outcome variables and covariates. The total number of events and crude injury rates were calculated. To compare outcomes of all immigrants and nonimmigrants, multiple variable Poisson regression models adjusting for overdispersion were used to compute rate ratios (RRs) with 95\% confidence intervals (CIs) using 2011-2012 data. For each model, variables were selected a priori and included in the regression analysis. The main model included both immigrants and nonimmigrants, but because the initial descriptive results suggested different associations between sociodemographics and injury in immigrants and nonimmigrants, we also carried out a stratified analysis. To determine causespecific injury risk, crude injury rates for each cause were calculated by immigrant status. Subsequently, multiple variable Poisson regression models were used to compare causespecific RRs of injury by immigrant status. All statistical modelling was carried out using SAS Enterprise Guide, version 6.1 (SAS Institute).

\section{Ethics approval}

Research ethics board approval was obtained from The Hospital for Sick Children and Sunnybrook Health Sciences Centre in Toronto.

\section{Results}

There was an annualized mean of 3173391 nonimmigrants and 910258 immigrants included in the study. Compared with nonimmigrants, immigrants had a greater proportion of young, urban and lower neighbourhood income quintile individuals (Table 1). Overall age- and sex-standardized annual rates of unintentional injuries were 11749 emergency department visits per 100000 population, 267 hospital admissions per 100000 population and 12 deaths per 100000 population.

Table 2 shows rates of unintentional injury-related events by immigrant status. Compared with nonimmigrants, immigrants had lower rates of visits to the emergency department, admissions to hospital and deaths from unintentional injury across all age groups. Rates of injury-related visits to the emergency department by age differed between immigrants and nonimmigrants. Among immigrants, children in the youngest age group had the highest visit rates (7754/100 000 population), whereas among nonimmigrants, children in the 15- to 19-year age group had the highest rates (15 940/100 000 population). Injury-related admissions to hospital and deaths showed similar patterns by age in immigrants and nonimmigrants, with the highest rates in the 15- to 19- and 20- to 24-year age groups. Among nonimmigrants, children in the lowest neighbourhood income quintile had the highest rates of visits to the emergency department for injury. This is in contrast to findings among immigrants, where those in the highest income quintile had the highest rates of visits. These differential trends in neighbourhood income quintile and injury rates were not seen for injuries that required hospital admission or caused death. Rural and male populations had higher rates of injury in both immigrant and nonimmigrant groups, regardless of injury severity.

\begin{tabular}{|c|c|c|}
\hline Characteristic & $\begin{array}{c}\text { Nonimmigrants, } \\
\text { no. (\%) } \\
n=3171110\end{array}$ & $\begin{array}{c}\text { Immigrants, no. (\%) } \\
n=914372\end{array}$ \\
\hline \multicolumn{3}{|l|}{ Age group, yr } \\
\hline $0-4$ & $544938(17.2)$ & $186770(20.4)$ \\
\hline $5-9$ & $565129(17.8)$ & $186052(20.3)$ \\
\hline $10-14$ & $613955(19.4)$ & $191901(21.0)$ \\
\hline $15-19$ & 719693 (22.7) & $178666(19.5)$ \\
\hline $20-24$ & 727395 (22.9) & $170983(18.7)$ \\
\hline \multicolumn{3}{|l|}{ Sex } \\
\hline Female & 1547106 (48.8) & $445381(48.7)$ \\
\hline Male & 1624004 (51.2) & 468991 (51.3) \\
\hline \multicolumn{3}{|c|}{ Neighbourhood income quintile } \\
\hline Q1 (lowest) & $563314(17.8)$ & 268317 (29.3) \\
\hline Q2 & $571014(18.0)$ & $199314(21.8)$ \\
\hline Q3 & $625353(19.7)$ & $183429(20.1)$ \\
\hline Q4 & $698687(22.0)$ & $160234(17.5)$ \\
\hline Q5 (highest) & $712742(22.5)$ & $103078(11.3)$ \\
\hline \multicolumn{3}{|l|}{ Rurality } \\
\hline Urban & $2731160(86.1)$ & 903371 (98.8) \\
\hline Rural & 439950 (13.9) & $11001(1.2)$ \\
\hline
\end{tabular}




\begin{tabular}{|c|c|c|c|c|c|c|c|c|c|c|c|c|}
\hline \multirow[b]{3}{*}{ Characteristic } & \multicolumn{4}{|c|}{ Emergency department visits } & \multicolumn{4}{|c|}{ Hospital admissions } & \multicolumn{4}{|c|}{ Deaths } \\
\hline & \multicolumn{2}{|c|}{ Immigrants } & \multicolumn{2}{|c|}{ Nonimmigrants } & \multicolumn{2}{|c|}{ Immigrants } & \multicolumn{2}{|c|}{ Nonimmigrants } & \multicolumn{2}{|c|}{ Immigrants } & \multicolumn{2}{|c|}{ Nonimmigrants } \\
\hline & $n$ & $\begin{array}{c}\text { Rate } \\
\text { per } \\
100000 \\
\text { population }\end{array}$ & $n$ & $\begin{array}{c}\text { Rate } \\
\text { per } \\
100000 \\
\text { population }\end{array}$ & $n$ & $\begin{array}{c}\text { Rate } \\
\text { per } \\
100000 \\
\text { population }\end{array}$ & $n$ & $\begin{array}{c}\text { Rate } \\
\text { per } \\
100000 \\
\text { population }\end{array}$ & $n$ & $\begin{array}{c}\text { Rate } \\
\text { per } \\
100000 \\
\text { population }\end{array}$ & $n$ & $\begin{array}{c}\text { Rate } \\
\text { per } \\
100000 \\
\text { population }\end{array}$ \\
\hline \multicolumn{13}{|l|}{ Age group, yr } \\
\hline $0-4$ & 71791 & 7754.4 & 307481 & 11288.5 & 1702 & 183.8 & 6653 & 244.2 & 30 & 3.2 & 184 & 6.7 \\
\hline $5-9$ & 54354 & 5827.5 & 273305 & 9637.1 & 1450 & 155.4 & 5781 & 203.8 & 14 & 1.5 & 60 & 2.1 \\
\hline $10-14$ & 62561 & 6542.3 & 450183 & 14538.9 & 1207 & 126.1 & 6837 & 220.7 & 16 & 1.7 & 115 & 3.7 \\
\hline $15-19$ & 61219 & 6794.2 & 569594 & 15940.5 & 1879 & 208.8 & 14664 & 410.4 & 83 & 9.2 & 738 & 20.6 \\
\hline $20-24$ & 57815 & 6895.1 & 495019 & 13587.1 & 1754 & 209.3 & 12898 & 354.0 & 165 & 19.7 & 1140 & 31.3 \\
\hline \multicolumn{13}{|l|}{ Sex } \\
\hline Female & 117063 & 5201.2 & 843147 & 10869 & 2948 & 133.0 & 17647 & 225.0 & 88 & 4.2 & 613 & 7.6 \\
\hline Male & 190677 & 8210.0 & 1252435 & 15311 & 5044 & 219.7 & 29186 & 353.6 & 220 & 10.6 & 1624 & 19.1 \\
\hline \multicolumn{13}{|c|}{ Neighbourhood income quintile } \\
\hline Q1 (lowest) & 87203 & 6508.3 & 408717 & 14407.9 & 2550 & 192.4 & 9858 & 341.0 & 112 & 9.0 & 606 & 20.0 \\
\hline Q2 & 63893 & 6418.4 & 394427 & 13693.9 & 1748 & 178.4 & 8768 & 299.4 & 65 & 7.3 & 411 & 13.3 \\
\hline Q3 & 60562 & 6615.2 & 410798 & 13055.1 & 1513 & 167.2 & 8989 & 283.0 & 56 & 7.0 & 403 & 12.4 \\
\hline Q4 & 57083 & 7129.9 & 444584 & 12700.7 & 1332 & 169.1 & 9568 & 272.2 & 53 & 7.7 & 422 & 12.0 \\
\hline Q5 (highest) & 38999 & 7508.3 & 437056 & 12124.3 & 849 & 164.7 & 9650 & 265.7 & 22 & 4.8 & 395 & 10.6 \\
\hline \multicolumn{13}{|l|}{ Rurality } \\
\hline Urban & 300162 & 6650.2 & 1667436 & 12146.5 & 7853 & 176.2 & 38255 & 275.8 & 298 & 7.3 & 1698 & 11.8 \\
\hline Rural & 7578 & 13652.5 & 428146 & 19218.8 & 139 & 257.3 & 8578 & 383.1 & 10 & 18.7 & 539 & 23.7 \\
\hline
\end{tabular}

After adjustment for age, sex, income and rurality, immigrants had a 44\% lower risk of unintentional injury overall compared with nonimmigrants (RR 0.56 , 95\% CI $0.54-$ 0.59). Predictors of injury included male sex (RR 1.39, $95 \%$ CI 1.35-1.44) and rural residence ( $\mathrm{RR}=1.59$, 95\% CI $1.53-$ 1.66). In the models stratified by immigrant status, age and income predicted injury differently in immigrants and nonimmigrants (Table 3). Young age had the highest risk of injury among immigrants, whereas adolescents had the highest risk of injury among nonimmigrants. Low income was associated with a lower risk of injury among immigrants, whereas it was associated with higher risk of injury among nonimmigrants.

Table 4 describes cause-specific injury risk by immigrant status. Risk of unintentional injury was lower across all causes of injury among immigrants. The most common causes of unintentional injury in both groups were falls and being struck. Motor vehicle injuries were the most common cause of death among immigrants (1.3 deaths/100 000 population) and nonimmigrants (3.6 deaths/100 000 population), followed by poisoning (0.6 deaths/100 000 population among immigrants; 1.9 deaths/100 000 population among nonimmigrants).

\section{Interpretation}

In this large, population-based study, we report a 44\% lower risk of unintentional injury among immigrant children and youth compared with children and youth from nonimmigrant families. The reduced risk was seen across all causes of injury. Income, which has traditionally had an inverse association with injuries, ${ }^{3,8,10,14}$ had the opposite association in our immigrant population for visits to the emergency department - high neighbourhood income quintile was associated with a high risk of injury among immigrants. Adolescents had the highest risk of injury among nonimmigrants; among immigrants, risk was highest in infants and young children.

A Danish registry study evaluated unintentional injuries in children of foreign-born mothers and reported lower rates compared with children of Danish mothers. Lower rates of injury were seen for all causes except burns and foreign bodies in the ear. ${ }^{9}$ Smaller Canadian studies have shown a 1.35-times higher relative risk of bicycling-related injuries in new immigrants ${ }^{41}$ and a higher risk of serious falls from buildings ${ }^{21}$ and from falling televisions ${ }^{22}$ in immigrants compared with nonimmigrants. A few studies have evaluated injury fatalities in foreign-born populations and found mixed 
results. Karimi and colleagues showed that compared with native Swedes, children with foreign backgrounds had higher risk of injury fatality, with a particularly high risk of transportation- and drowning-related deaths in boys and fire/flame and fall deaths in girls. ${ }^{31}$ Similarly, Kahl and colleagues ${ }^{42}$ reported higher rates of drowning in young immigrant boys compared with native Germans, and Stirbu and colleagues $^{43}$ have shown higher risk of injury mortality in ethnic minorities in the Netherlands. These studies are in contrast to ours and that of Sorenson and colleagues, ${ }^{44}$ in which immigrant children have lower risk of injury fatality.

The associations with high injury risk and low socioeconomic status and adolescent age are well-established in the general populations of Canada and other countries. ${ }^{1,7,9,13,35}$ However, our study suggests that this may not be the case in all subgroups. Our findings show different causal pathways may exist for injury in immigrants, and strategies for prevention should be targeted accordingly. One other study that tested the association of socioeconomic status and injuries in immigrant children reported that, among foreign-born children in Sweden, the risk of admission to hospital and death owing to unintentional injuries is higher in children with the lowest parental education compared with those with the highest parental education. ${ }^{23}$

The lower observed rates of unintentional injury in Ontario's immigrant population may be explained by Canada's immigrant selection and settlement policies, which target healthy ${ }^{45}$ highly educated, motivated and resourceful people. Certain sociocultural factors in foreign-born families, such as reduced risk-taking behaviours (e.g., substance use), ${ }^{25}$ familial and social support systems that promote healthy behaviours and a sense of well-being ${ }^{32}$ and less physical activity, especially through high-risk sporting activities, may explain some of our findings. This latter explanation may account for the higher rates of injuries in nonimmigrant adolescents. Socioeconomic differences in injury rates, particularly for milder injuries that do not require admission to hospital, may be due to different care-seeking behaviours among immigrants ${ }^{46-48}$ or disparities in access to primary care. ${ }^{49}$

\section{Strengths and limitations}

Strengths of this study include the large sample size and the use of population-level databases. This study is distinguished from existing ones, which are based on smaller cohorts, rely on self-report or focus exclusively on adults.

Limitations include not capturing minor injuries that did not result in an emergency department or hospital interaction that may have been treated in a medical office or at home, or injuries in people who leave the province. Careseeking behaviour may differ between study groups, which may have affected results for minor injuries. Better information on contributing factors (alcohol, drugs, behavioural disorders and education levels) would have helped to contextualize our results. Misclassification of some immigrants (i.e., temporary/undocumented immigrants, immigrant mothers who landed in Canada before 1985, immigrants who landed in another province or foreign-born Canadian citizens who

\begin{tabular}{|c|c|c|}
\hline \multicolumn{3}{|c|}{$\begin{array}{l}\text { Table 3: Rate ratios of unintentional injuries for children ano } \\
\text { youth ages } 0-24 \text { years by immigration status, 2011-2012 }\end{array}$} \\
\hline Immigration status & \multicolumn{2}{|c|}{$\begin{array}{c}\text { Overall adjusted }{ }^{*} \text { model } \\
\text { RR }(95 \% \mathrm{Cl})\end{array}$} \\
\hline Immigrants & \multicolumn{2}{|c|}{$0.56(0.54-0.59)$} \\
\hline Nonimmigrants & \multicolumn{2}{|c|}{ Reference } \\
\hline & \multicolumn{2}{|c|}{$\begin{array}{l}\text { Stratified models } \\
\text { RR }(95 \% \mathrm{Cl})^{*}\end{array}$} \\
\hline Characteristic & $\begin{array}{l}\text { Immigrants } \\
n=999951\end{array}$ & $\begin{array}{l}\text { Nonimmigrants } \\
n=3296559\end{array}$ \\
\hline \multicolumn{3}{|l|}{ Age group, yr } \\
\hline $0-4$ & $1.23(1.16-1.31)$ & $0.91(0.87-0.95)$ \\
\hline $5-9$ & $0.92(0.87-1.00)$ & $0.80(0.76-0.84)$ \\
\hline $10-14$ & $1.05(0.98-1.12)$ & $1.23(1.18-1.28)$ \\
\hline $15-19$ & $1.02(0.95-1.09)$ & $1.22(1.17-1.27)$ \\
\hline $20-24$ & Reference & Reference \\
\hline \multicolumn{3}{|l|}{ Sex } \\
\hline Male & $1.51(1.45-1.58)$ & $1.37(1.34-1.41)$ \\
\hline Female & Reference & Reference \\
\hline \multicolumn{3}{|c|}{ Neighbourhood income quintile } \\
\hline Q1 (lowest) & $0.88(0.82-0.94)$ & $1.13(1.08-1.18)$ \\
\hline Q2 & $0.86(0.80-0.92)$ & $1.10(1.05-1.15)$ \\
\hline Q3 & $0.89(0.83-0.95)$ & $1.07(1.02-1.12)$ \\
\hline Q4 & $0.95(0.89-1.02)$ & $1.05(1.01-1.09)$ \\
\hline Q5 (highest) & Reference & Reference \\
\hline \multicolumn{3}{|l|}{ Rurality } \\
\hline Rural & $1.98(1.74-2.25)$ & $1.58(1.53-1.64)$ \\
\hline Urban & Reference & Reference \\
\hline
\end{tabular}

subsequently moved to Ontario) may have also affected our results. Results may not be generalizable to temporary or undocumented immigrants. In addition, paternal immigration status may be important in understanding risk of injury, but linkage was not feasible.

\section{Conclusion}

Children and youth from immigrant families have a lower risk of unintentional injury compared with those from nonimmigrant families. Sociodemographic factors that traditionally predict injury in most populations do not apply universally to immigrant populations, suggesting different causal pathways for injury. Ongoing epidemiologic studies involving immigrants can help identify protective factors within this group that may be helpful for improving injury prevention in the general population while maintaining healthy and active development. 
Table 4: Adjusted rate ratios and crude rates of cause-specific unintentional injury-related emergency department visits, hospital admissions and deaths in children and youth ages 0-24 years by immigration status, annualized 2008-2012

\begin{tabular}{|c|c|c|c|}
\hline Cause of injury & $\begin{array}{c}\text { Adjusted }^{*} \mathrm{RR}(95 \% \mathrm{Cl}) \\
\text { (Reference }=\text { nonimmigrants) }\end{array}$ & $\begin{array}{l}\text { Crude injury rate per } \\
100000 \text { immigrants }\end{array}$ & $\begin{array}{l}\text { Crude injury rate per } \\
100000 \text { nonimmigrants }\end{array}$ \\
\hline Fall & $0.60(0.58-0.62)$ & 2108.6 & 3574.9 \\
\hline Struck by/against & $0.48(0.45-0.51)$ & 1347.6 & 3069.3 \\
\hline Overexertion & $0.59(0.54-0.64)$ & 568.4 & 1104.2 \\
\hline Cut/pierce & $0.47(0.44-0.50)$ & 372.9 & 917.5 \\
\hline Natural/environmental & $0.40(0.37-0.44)$ & 183.0 & 511.9 \\
\hline $\begin{array}{l}\text { Other bicycle } \\
\text { (Non-motor vehicle collision) }\end{array}$ & $0.53(0.48-0.58)$ & 165.8 & 327.8 \\
\hline Poisoning & $0.61(0.57-0.65)$ & 136.6 & 230.6 \\
\hline Motor vehicle traffic & $0.73(0.69-0.77)$ & 308.5 & 468.4 \\
\hline Hot object/scald & $0.71(0.64-0.78)$ & 88.5 & 132.0 \\
\hline Fire/flame & $0.39(0.32,0.46)$ & 12.4 & 40.5 \\
\hline $\begin{array}{l}\text { Other pedestrian } \\
\text { (Non-motor vehicle collision) }\end{array}$ & $0.74(0.63-0.86)$ & 10.3 & 15.9 \\
\hline Machinery & $0.55(0.47-0.64)$ & 17.2 & 40.7 \\
\hline Suffocation & $0.68(0.54-0.84)$ & 5.5 & 8.2 \\
\hline Other land transport & $0.23(0.19-0.26)$ & 36.6 & 230.8 \\
\hline Drowning & $0.69(0.53-0.91)$ & 2.9 & 4.0 \\
\hline Firearm & $0.43(0.33-0.56)$ & 3.3 & 7.1 \\
\hline Other or not specified & $0.64(0.61-0.68)$ & 1335.9 & 2257.2 \\
\hline
\end{tabular}

\section{References}

1. Sminkey L. World report on child injury prevention. Inj Prev 2008;14:69.

2. Facts on injury. Ottawa: Public Health Agency of Canada; 2006. Available: www.phac-aspc.gc.ca/injury-bles/facts-eng.php (accessed 2016 Jan. 6).

3. Macpherson AK, Cernat G, Schull MJ. Injuries in Ontario. Healthc Q 2006; 9:29-30

4. Fridman L, Fraser-Thomas JL, McFaull SR, et al. Epidemiology of sportsrelated injuries in children and youth presenting to Canadian emergency departments from 2007-2010. BMC Sports Sci Med Rehabil 2013;5:30.

5. Wattie N, Cobley S, Macpherson A, et al. Injuries in Canadian youth ice hockey: the influence of relative age. Pediatrics 2007;120:142-8.

6. Macpherson AK, To TM, Parkin PC, et al. Urban/rural variation in children's bicycle-related injuries. Accid Anal Prev 2004;36:649-54.

7. Macpherson AK, Jones J, Rothman L, et al. Safety standards and socioeconomic disparities in school playground injuries: a retrospective cohort study. BMC Public Health 2010;10:542.

8. Agran PF, Winn DG, Anderson CL, et al. Family, social, and cultural factors in pedestrian injuries among Hispanic children. Inj Prev 1998;4:188-93.

9. Laursen B, Møller H. Unintentional injuries in children of Danish and foreign-born mothers. Scand 7 Public Health 2009;37:577-83.

10. Birken CS, Parkin PC, To T, et al. Trends in rates of death from unintentional injury among Canadian children in urban areas: influence of socioeconomic status. CMAF 2006; 175:867.

11. Birken CS, Parkin PC, To T, et al. Neighborhood socioeconomic status and homicides among children in urban Canada. Pediatrics 2009;123:e815-9.

12. Parkin PC, Degroot J, Macpherson A, et al. Canadian parents' attitudes and beliefs about bicycle helmet legislation in provinces with and without legislation. Chronic Dis Inj Can 2014:34:8-11.

13. Macpherson AK, To TM, Macarthur C, et al. Impact of mandatory helmet legislation on bicycle-related head injuries in children: a population-based study. Pediatrics 2002;110:e60.

14. Macpherson AK, Macarthur C, To TM, et al. Economic disparity in bicycle helmet use by children six years after the introduction of legislation. Inj Prev 2006;12:231-5
15. Ontario Regulation Building Code Act, 2004. Toronto: Service Ontario; 2004 Available: www.e-laws.gov.on.ca/html/source/regs/english/2004/elaws_src regs_r04023 e.htm (accessed 2016 Jan. 6).

16. CAN/CSA-Z614 - Children's playspaces and equipment. 4th ed. Hamilton (ON): Canadian Centre for Occupational Health and Safety; 2007.

17. Howard AW, MacArthur C, Willan A, et al. The effect of safer play equipment on playground injury rates among school children. CMA7 2005;172:1443-6.

18. Macpherson A, Spinks A. Bicycle helmet legislation for the uptake of helmet use and prevention of head injuries. Cochrane Database Syst Rev 2007;(2):CD005401.

19. Spinks A, Wasiak J, Cleland H, et al. Ten-year epidemiological study of pediatric burns in Canada. 7 Burn Care Res 2008;29:482-8.

20. Facts and figures 2011 - Immigration overview: permanent and temporary residents. Ottawa: Citizenship and Immigration Canada; 2013.

21. Mayer L, Meuli M, Lips U, et al. The silent epidemic of falls from buildings: analysis of risk factors. Pediatr Surg Int 2006;22:743-8.

22. Mills J, Grushka J, Butterworth S. Television-related injuries in children the British Columbia experience. 7 Pediatr Surg 2012;47:991-5.

23. Beiki O, Karimi N, Mohammadi R. Parental educational level and injury incidence and mortality among foreign-born children: a cohort study with 46 years follow-up. 7 Inj Violence Res 2014;6:37-43.

24. Schyllander J, Janson S, Nyberg C, et al. Case analyses of all children's drowning deaths occurring in Sweden 1998-2007. Scand 7 Public Health 2013; 41:174-9.

25. Xiang H, Yu S, Zhang X, et al. Behavioral risk factors and unintentional injuries among U.S. immigrant adults. Ann Epidemiol 2007;17:889-98.

26. Chong VE, Lee WS, Victorino GP. Potential disparities in trauma: the undocumented Latino immigrant. 7 Surg Res 2014;191:251-5.

27. Grzywacz JG, Arcury TA, Marin A, et al. The organization of work: implications for injury and illness among immigrant Latino poultry-processing workers. Arch Environ Occup Health 2007;62:19-26.

28. Arcury TA, Cartwright MS, Chen H, et al. Musculoskeletal and neurological injuries associated with work organization among immigrant Latino women manual workers in North Carolina. Am f Ind Med 2014;57:468-75. 
29. Menéndez CK, Havea SA. Temporal patterns in work-related fatalities among foreign-born workers in the US, 1992-2007. 7 Immigr Minor Health 2011;13:954-62

30. Singh GK, Siahpush M. Ethnic-immigrant differentials in health behaviors, morbidity, and cause-specific mortality in the United States: an analysis of two national data bases. Hum Biol 2002;74:83-109.

31. Karimi N, Beiki O, Mohammadi R. Risk of fatal unintentional injuries in children by migration status: a nationwide cohort study with 46 years' followup. Inj Prev 2015;21:e80-7.

32. Mendoza FS. Health disparities and children in immigrant families: a research agenda. Pediatrics 2009;124(Suppl 3):S187-95.

33. Saunders NR, To T, Parkin PC, et al. Emergency department revisits by urban immigrant children in Canada: a population-based cohort study. $\mathcal{F}$ Pediatr 2016;170:218-26.

34. Data dictionary: library. Toronto: Institute for Clinical Evaluative Sciences. Available: https://datadictionary.ices.on.ca/Applications/DataDictionary/ Library.aspx? Library=CIC (accessed 2016 Apr. 11).

35. Dissemination area (DA). Ottawa: Statistics Canada; 2012. Available: http:// www12.statcan.gc.ca/census-recensement/2011/ref/dict/geo021-eng.cfm (accessed 2014 Oct. 9)

36. Kralj B. Measuring rurality — RIO2008_BASIC: methodology and results. Toronto: Ontario Medical Association; 2009.

37. Dataset dictionary: data repository. Toronto: Institute for Clinical Evaluative Sciences; 2013. Available: https://datadictionary.ices.on.ca/Applications/Data Dictionary/Default.aspx (accessed 2016 Jan. 6).

38. Chiu M, Lebenbaum M, Lam K, et al. Describing the linkages of the Immigration, Refugees and Citizenship Canada Permanent Resident Data and Vital Statistics Death Registry to Ontario's administrative health database. BMC Med Inform Decis Mak 2016;16:135.

39. Annest JL, Hedegaard H, Chen LH, et al. Proposed framework for presenting injury data using ICD-10-CM external cause of injury codes. Atlanta: Centers for Disease Control and Prevention; 2014.

40. Peden M, Oyegbite K, Ozanne-Smith J, editors. World report on child injury prevention. Geneva: World Health Organization, UNICEF; 2008.

41. Davison CM, Torunian M, Walsh P, et al. Bicycle helmet use and bicyclingrelated injury among young Canadians: an equity analysis. Int 7 Equity Health 2013;12:48.

42. Kahl H, Dortschy R, Ellsasser G. Injuries among children and adolescents (1-17 years) and implementation of safety measures. Results of the nationwide German Health Interview and Examination Survey for Children and Adolescents (KiGGS) [article in German]. Bundesgesundheitsblatt Gesundheitsforschung Gesundheitsschutz 2007;50:718-27.

43. Stirbu I, Kunst AE, Bos V, et al. Injury mortality among ethnic minority groups in the Netherlands. F Epidemiol Community Health 2006;60:249-55.

44. Sorenson SB, Shen H. Mortality among young immigrants to California: injury compared to disease deaths. 7 Immigr Health 1999;1:41-7.

45. Kwak K, Rudmin F. Adolescent health and adaptation in Canada: examination of gender and age aspects of the healthy immigrant effect. Int 7 Equity Health 2014;13:103.

46. Guzder J, Yohannes S, Zelkowitz P. Helpseeking of immigrant and native born parents: a qualitative study from a montreal child day hospital. 7 Can Acad Child Adolesc Psychiatry 2013;22:275-81.
47. Moineddin R, Meaney C, Agha M, et al. Modeling factors influencing the demand for emergency department services in Ontario: a comparison of methods. BMC Emerg Med 2011;11:13.

48. Javier JR, Wise PH, Mendoza FS. The relationship of immigrant status with access, utilization, and health status for children with asthma. Ambul Pediatr 2007;7:421-30.

49. Campbell RM, Klei AG, Hodges BD, et al. A comparison of health access between permanent residents, undocumented immigrants and refugee claimants in Toronto, Canada. 7 Immigr Minor Health 2014;16:165-76.

Affiliations: The Hospital for Sick Children (Saunders, Guttmann); Department of Pediatrics (Saunders, Guttmann), University of Toronto; Institute for Clinical Evaluative Sciences (Saunders, Macpherson, Guan, Sheng, Guttmann); York University (Macpherson); Institute of Health Policy, Management and Evaluation (Guttmann); Dalla Lana School of Public Health (Guttmann), University of Toronto; Child Health Evaluative Sciences (Guttmann), SickKids Research Institute, Toronto, Ont.

Contributors: Natasha Saunders conceptualized and designed the study, interpreted the results, drafted the initial manuscript, revised the manuscript, and approved the final manuscript as submitted. Lisa Sheng and Jun Guan analyzed the data, revised the manuscript, and approved the final manuscript as submitted. Alison Macpherson and Astrid Guttmann conceptualized and designed the study, interpreted the results, revised the manuscript, and approved the final manuscript as submitted. All authors approved the final manuscript as submitted and agreed to be accountable for all aspects of the work.

Funding: Astrid Guttmann and Alison Macpherson are funded through Applied Chairs in Child Health Services and Policy Research from the Canadian Institutes for Health Research.

Supplemental information: For reviewer comments and the original submission of this manuscript, please see www.cmajopen.ca/content $/ 5 / 1 /$ E90/suppl/DC1

Disclaimer: This study was supported by the Institute for Clinical Evaluative Sciences (ICES), which is funded by an annual grant from the Ontario Ministry of Health and Long-Term Care (MOHLTC). The opinions, results and conclusions reported in this article are those of the authors and are independent from the funding sources. No endorsement by ICES or the Ontario MOHLTC is intended or should be inferred. Parts of this material are based on data and information compiled and provided by the Canadian Institute for Health Information (CIHI) and Immigration, Refugees and Citizenship Canada (IRCC). The analyses, conclusions, opinions and statements expressed in this paper are those of the authors and not necessarily those of CIHI and IRCC. 